\title{
Editorial: Importance of CPD for consultant psychiatrists
}

\author{
Mark Aveline
}

In a time of great organisational change and everincreasing demands from external bodies for demonstrations of value from the clinical, teaching, audit and research activities that make up psychiatric work, continuing professional development (CPD) can appear to be a further burden and one too many. "Enough is enough", some may protest. This reaction is enhanced if CPD is seen as an imposed bureaucracy of little relevance to clinical practice, merely a further series of hoops through which tired doctors have to jump. This is what we must strive to avoid; this is not the way to reap the rewards that CPD can bring.

If it is not too much of a tautology, CPD is an opportunity for professional development which will enhance relevant clinical skills and expertise. I stress the words "opportunity" and "relevant". Knowledge and skills are enhanced by practice and critical reflection on what one does and what the literature has to teach. Both elements are crucial lest practice become mindless repetition and knowledge mere prejudice. It is from practice that we gain clinical wisdom and facility. It is from a commitment to CPD that we maintain and develop expertise. For the CPD registrant, what are the sticks and the carrots?

Being in good standing with one's CPD is certain to become more important for the holding of some College positions, and the same is likely to apply for employment as the value of CPD becomes accepted. The College has already stipulated that College tutors and examiners be registered for CPD and this requirement may soon be extended to educational supervisors. For employers, a commitment to CPD will make posts more attractive and help with risk management. It is a short step for purchasers to insist when placing contracts that career-grade staff are up-to-date with their CPD. Furthermore, the clinician's personal risk management in court or before the General Medical Council will be buttressed by their CPD. Broadly speaking, these are the sticks. What of the carrots?
The College has put in place a system for the recognition of a variety of learning experiences and has created this journal. The explicit message to clinicians is that CPD is important, and it takes time and money. The key step for making CPD truly useful is the evolution of a personal educational plan, tailored to the doctor's own situation. Then, the learning will be relevant and engaging.

My Trust has created the position of educational supervisor to facilitate the CPD of career-grade staff. Although the task is substantial, with 64 eligible colleagues, the intention is for all to have an educational plan and annual review. Educationally, three parties have a legitimate interest in the plan: the doctor, the service in which he or she works and the Trust itself. Looking both to the short term (one year) and the longer term (two to three years), the doctor identifies learning needs, which then inform the plan of engagement. Some learning, such as resuscitation and the handling of dangerous situations, is best provided collectively but other needs have a more individual solution. Colleagues often want help with clinical management in a way that formal educational provision through lectures and seminars does not provide. Ongoing supervision of clinical work, either with an external expert or in a peer group, or consultation with colleagues with a different area of expertise satisfies that need. This approach, a variant of module $B$ in the College scheme, requires time but not necessarily finance. In CPD, we need to think educationally first and foremost, rather than procedurally through the accumulation of categorical credits.

CPD is a way of providing structured, continuous medical education from qualification to retirement. It reflects the medical profession's commitment to self-regulation, and its successful implementation requires reserved time and imaginative solutions. Through being relevant and self-directed, it could also put the fun back into practice.

Mark Aveline is Educational Supervisor and Consultant Psychotherapist at the Nottingham Healthcare NHS Trust. He is based at the Nottingham Psychotherapy Unit, St Ann's House, 114 Thorneywood Mount, Nottingham NG3 2PZ. 